\title{
Potential of Herbal Drug and Antibiotic Combination Therapy: A New Approach to Treat Multidrug Resistant Bacteria
}

\author{
Bhardwaj M, Singh BR*, Sinha DK, Kumar V, Prasanna Vadhana OR, Varan Singh S, Nirupama KR, Pruthvishree and Archana Saraf BS \\ Division of Epidemiology, ICAR-Indian Veterinary Research Institute, Izatnagar-243122, Uttar Pradesh, India
}

"Corresponding author: Singh BR, Act. Head of Division of Epidemiology, ICAR-IVRI, Izatnagar-243122, Uttar Pradesh, India, Tel: +91-8449033222; E-mail: brs1762@ivri.res.in

Received date: October 24, 2016; Accepted date: November 16, 2016; Published date: November 20, 2016

Copyright: (c) 2016 Bhardwaj M, et al. This is an open-access article distributed under the terms of the Creative Commons Attribution License, which permits unrestricted use, distribution, and reproduction in any medium, provided the original author and source are credited.

\begin{abstract}
The word antibiotic emerges from antibiosis mean against life; it is also because of the fact that antibiotics affect our life. Antimicrobial drug use is rampant not only in therapeutics but also in livestock production leading to continuous contamination of our environment. Indiscriminate use of antibiotics has led to emergence and spread of antimicrobial drug resistance in microbes including pathogens leading to an imbalance in the microbiota of our system and the environment. Ominous distribution of antimicrobial drug resistance in microbes, and still then the use of antimicrobials cause several social, economic and psychological complications. At present the challenges are several with us, viz.: 1) The antibiotics, once considered miracle drugs, are now not miraculous and there is hardly any antibiotic available to treat Multiple Drug Resistant (MDR), Extended Drug Resistant (XDR), and Total Drug Resistant (TDR) microbes with a promise to cure; 2) There are no alternatives to antibiotics at hand or insight at present; 3) There are no policies to regulate antimicrobial drug use in most of the developing world if any they have not been implemented; 4) Antimicrobial drug-resistant strains are everywhere even in environment naive to human invasion; 5) Those are susceptible may get MDR strains from their clinicians; and 6) Clinicians usually ignore the physiological and psychological effects of antimicrobials while recommending the therapy and are least bothered for the side effects of antimicrobial chemotherapy. In treatment of number of infections, two or more drugs are however, the therapeutic efficacy of the combination depend interactions of drugs combined. Synergistic combinations help to reduce emergence of resistant mutants, toxicity, exhibit more antimicrobial activity and more effective against mixed infections. However, only little is understood about the combination of herbal antimicrobials and antibiotics. Herein the existing information on the synergy between antibiotics and herbal antimicrobials is reviewed.
\end{abstract}

Keywords: Bacteria; Herbs; Antibiotics; Resistance; Synergy; Antagonism; Interaction

\section{Introduction}

Due to emergence of bacterial strains resistant due to inappropriate prescribing, inappropriate use, use of antibiotics as substitute for sanitation, as growth enhancers, aerial spray of antibiotics to control plant diseases [1] and as vaccine preservative [2]. The antibiotics are also responsible for large number of side effects, so plant products are currently of growing interest as future antimicrobial agents [3]. The short comings of antibiotic therapy lead to the generation of new antibacterial drugs from natural resources like herbs.

The plant products proved as more promising antimicrobials in spite of the fact that their antimicrobial activity is milder than commercially available antibiotics $[4,5]$. The essential oils have been used for many years for their curative potential. Herbal drugs alternatively can be used in combination with antibiotics with enhanced activity against bacterial infections. In support of it, Abascal and Yarnell [1] indicated that there are various mechanisms due to which microbes usually do not become resistant to herbs viz., herbal drugs may act synergistically with drugs to kill microbes, herbs may inactivate/destroy enzymes produced by bacteria to degrade antibiotics, herbal drugs may inhibit the action of efflux pumps making bacteria unable to remove antibiotics from their body, etc. The research indicates that the combination therapy should be applied in veterinary and human medicine as an alternative therapy against bacterial infections. To exploit the synergistic combinations, it is important to determine the optimal ratio and dose of antimicrobials. The evaluation of the synergistic or antagonistic effect of antimicrobials can improve the use of antibiotics. Previously, the synergistic activity of amoxicillin with clavulanic acid against $\beta$-lactamase-producing strains of Haemophilus ducreyi was determined by agar dilution susceptibility testing [6]. Along with it, sulbactam and ampicillin were combined against methicillin-resistant staphylococci by the agar fixed ratio method, checkerboard dilution and by time killing curves [7]. Another $\beta$ lactamase inhibitor tazobactam combined with piperacillin and cefepime to access their activity by using time-kill assay against Klebsiella pneumoniae, Enterobacter cloacae, and Acinetobacter baumannii [8]. This approach was helpful in thinking about other drugs which can be combined with antibiotics.

It is important to know various types of effects that occur due to use of different drug combinations. The combined therapy has numerous benefits that include treatment of mixed infections, infection caused by specific causative organism, to increase antimicrobial activity, preventing need for long term antibiotic use, prevent emergence of multidrug resistant bacteria [9]. In other words, use of combination therapy would provide a better chance that at least one drug will be effective, thereby preventing the resistant mutant population from emerging as the dominant strain and causing therapeutic failure. In case of intra-abdominal infections that are usually caused by multiple organisms with a variety of aerobic and anaerobic bacteria. Antimicrobial combinations, such as a third-generation cephalosporin or a fluoroquinolones with metronidazole, can be used as a potential 
treatment option in these cases and can sometimes be more costeffective than a comparable single agent.

The present review summarizes the interactions between plant extracts/herbal drugs and standard antibiotics. It is observed that the drugs in combination affect differently as compared to use of the same $\operatorname{drug}(\mathrm{s})$ alone. Therefore, it is important to understand the potential interaction between herbal drugs and antibiotics for the selection of an appropriate combination.

\section{Antibiotic resistance}

Infectious diseases are the world's leading cause of premature deaths, killing almost 50,000 people every day [10]. With the continuous use of antibiotics, resistant microorganisms have emerged as a great threat. In addition to this problem, antibiotics are sometimes associated with adverse effects on the host which include hypersensitivity, immunosuppressant and allergic reactions. The treatment of infectious diseases with antimicrobial agents continues to present problems in modern-day medicine with many studies showing a significant increase in the incidence of bacterial resistance to several antibiotics. Drug resistance is driven by the misuse and overuse of antibiotics, which encourages bacteria to develop new ways of overcoming their presence. It has been a feature of medicine since Alexander Fleming's discovery of the first antibiotic, penicillin, in 1928. The spread of multiple antimicrobial-resistant pathogenic bacteria has been recognized by the World Organization for Animal Health (OIE), the Food and Agriculture Organization (FAO) and the World Health Organization (WHO) as a serious global human and animal health threat. The development of Antimicrobial Resistance (AMR) in bacteria is neither an unexpected nor a new phenomenon. It is, however, an increasingly troublesome situation because of the frequency with which new emerging resistance phenotypes are occurring among many bacterial pathogens and even commensal organisms. Resistance has been observed to essentially all of the antimicrobial agents currently approved for use in human and veterinary clinical medicine [11].

Antibiotics along with some feed additives have been used in the livestock and poultry industry in a large scale since a long time [12]. Implementation of a ban on antibiotics as the feed additive, forced us to go for some alternative treatment [12]. Emergence and spread of AMR and Multiple Drug Resistant (MDR) infections and antibioticassociated health ailments as a sequel of antibiotic therapy made researcher focus alternative medicine. Among alternates, the traditional herbal medicines making possible to identify novel bioactive compounds has attracted the attention of researchers' world over.

\section{Herbs and their therapeutic effects}

Herbal drugs have been used for several medication purposes throughout the world due to presence of important properties like antimicrobial, immunomodulatory, good health, therapeutic and healing properties that ensure prevention and cure of animal and human diseases [13]. In last few years, the requirement of herbal drugs has been increased due to their efficacy and potency in the treatment of various bacterial infections [13]. Due to the adaptation of civilized life over rural life, people have started to live along with companion animals which led to increasing in infectious and non-infectious agents, creating the problem of zoonotic pathogens. There are a number of herbal remedies which are constantly used as folk medicine in various tribal communities. Some of the most common herbal drugs are there like Tulsi (Ocimum sanctum), Cinnamon (Cinnamomum cassia), Black cohosh (Cimicifuga racemosa), Turmeric (Curcuma longa), Black pepper (Piper nigrum), Thyme (Thymus vulgaris), Ginger (Zingiber officinale), Ashawgandha (Withania somnifera), Neem (Azadirachta indica), Garlic (Allium sativum), Onion (Allium cepa), Clove (Syzgium aromaticum) etc. [12]. There are number of herbal drugs which have shown adverse effects when used on experimental animals. Akande [14] investigated hepatological, histological and renal function tests of Sprague-Dawley albino rats, to determine the possible effects on rat kidney and liver on oral exposure to Agyanom mixture, Bolex bitters and Remedia mixture. Histological features of mild to severe tubular necrosis were evident in the kidney tissues of all the experimental groups compared to the control, unlike in the liver tissues. The different type of herbs exihibit different properties shown in the Table 1.

\section{Herbs as antimicrobial}

Herbs have been used for many years as food additives and traditional medicine against a number of infectious agents. The most commonly used herbs that possess antimicrobial properties are garlic, black cumin, cloves, cinnamon, thyme, mustard etc. Herbs are potent antimicrobials and can replace synthetic preservatives like Butylated Hydroxyanisole (BHA) and Butylated Hydroxytoluene (BHT) used in the food industry [15]. According to WHO, herbs can be the best source to obtain a variety of drugs [16]. The herbs should be studied in a better way to understand their properties, safety, and efficiency [17-19].

A number of pathogenic bacteria have developed resistance to antibiotics that results into multi-drug resistance among bacteria [20]. Several studies have reported on potent antimicrobial properties of essential oils [21]. It is observed that there are complex interactions between different functional groups of herbal drugs like phenols, aldehydes, ketones, alcohols etc. [22]. It is a fact that the herbs containing cinnamaldehyde, citral, carvacrol, eugenol or thymol (aldehyde or phenol as functional groups) possess the higher antibacterial activity in comparison to other herbs/essential plant oils [23-25].

Lambert et al. [26] assessed minimum inhibitory concentration (MIC) of oregano essential oil (OEO) and two of its principal components, i.e., thymol and carvacrol, against Pseudomonas aeruginosa and Staphylococcus aureus. They observed an additive antimicrobial effect of carvacrol and thymol and thus the overall inhibition by OEO was much more than any of the two components used alone. Inhibition due to OEO is due to damage of membrane integrity, further affecting $\mathrm{pH}$, homeostasis and equilibrium of inorganic ions in the cytoplasm. Abascal and Yarnell [1] and recently Bhardwaj and coworkers [27] reported a synergistic effect of herbs with antibiotics to kill microbes.

\section{Herbal drugs: More effective in combination}

The herbal drugs including carvacrol, eugenol, cinnamaldehyde, thymol, terpenes are found effective against a number of bacteria like Staphylococcus aureus and Escherichia coli. The combinations of carvacrol, menthol, eugenol and thymol have been found to have synergistic, additive or antagonistic effects against different microbes. The antibacterial activities of eugenol, cinnamaldehyde, thymol, carvacrol estimated as MICs were 1600, 400, 400, and $400 \mathrm{mg} / \mathrm{L}$, 
Citation: Bhardwaj M, Singh BR, Sinha DK, Kumar V, Prasanna Vadhana OR, et al. (2016) Potential of Herbal Drug and Antibiotic Combination Therapy: A New Approach to Treat Multidrug Resistant Bacteria. Pharm Anal Acta 7: 523. doi:10.4172/2153-2435.1000523

Page 3 of 14

respectively. After combination, cinnamaldehyde/eugenol, thymol/ eugenol, carvacrol/eugenol, and thymol/carvacrol the MIC got reduced to $400,100,100$, and $100 \mathrm{mg} / \mathrm{L}$, respectively, showing synergistic effects [28]. Again in the year 2010, the study was conducted to assess the susceptibility of foodborne bacteria to single and paired combinations of the EOs of Lippia multiflora Moldenke, Mentha $x$ piperita L. and Ocimum basilicum and their major monoterpene alcohols, to detect synergistic, additive or antagonistic effects. The FIC indices ranged from 0.11 to 2.47 for paired combinations of L. multiflora, M. $x$ piperita and $O$. basilicum EOs. It was found that all paired combinations had synergistic effects on the inhibition of Enterococcus faecalis, Listeria monocytogenes and Escherichia coli. But eugenol with carvacrol and thymol did not show any synergistic action on any of the three bacteria and P. aeruginosa and Enterobacter aerogenes [29].

There are several kinds of drug interactions might be positive (synergy), negative (antagonism) or additive (Figure 1). The interactions are measured in terms of fractional inhibitory concentration (FIC).

\begin{tabular}{|c|c|c|c|}
\hline Herbal drug & Active constituent & Therapeutic action & Therapeutic use \\
\hline Ocimum sanctum & Eugenol, Urosolic acid & $\begin{array}{l}\text { Analgesis, Anti-inflammatory, Antipyretic, } \\
\text { Immunomodulatory }\end{array}$ & $\begin{array}{l}\text { Against Enteric organisms } \\
\text { pathogens and fish }\end{array}$ \\
\hline Cinnamomum cassia & $\begin{array}{ll}\text { Cinnamaldehyde, } & \text { 2-Hydroxy } \\
\text { Cinnamaldehyde } & \end{array}$ & Antimicrobial & $\begin{array}{l}\text { Food borne pathogens, Skin } \\
\text { infection }\end{array}$ \\
\hline Cimicifuga racemosa & $\begin{array}{l}\text { Cimicifugin, Racemosin, Actaealactone, } \\
\text { Fukinolic acid }\end{array}$ & Anti-inflammatory & $\begin{array}{l}\text { Dysmenorrhea, Discomfort of } \\
\text { menopause, Discomfort in late } \\
\text { pregnancy }\end{array}$ \\
\hline Curcuma longa & Cucurmin & Antimicrobial, Anti-inflammatory, Anti-neoplastic & $\begin{array}{l}\text { Detoxification, Insecticidal, Wound } \\
\text { Healing }\end{array}$ \\
\hline Piper nigrum & Piperine, Pentadienylpiperidine & Antimicrobial (Anti- Mycobacterial) & Asthama, Toxins \\
\hline Thymus vulgaris & Thymol and carvacrol & Antibacterial, Anticandidal, Antioxidant & Digestive disorders \\
\hline Zingiber officinale & $6,8,10$-gingerol, 6- shogoal & $\begin{array}{l}\text { Analgesis, Anti-inflammatory, Antipyretic, } \\
\text { Antimicrobial }\end{array}$ & Helicobacter pylori infection \\
\hline Withania somnifera & $\begin{array}{l}\text { Winthanolides, Withaferins, Dimeric } \\
\text { thiowinthanolide }\end{array}$ & $\begin{array}{l}\text { Analgesis, Anti-inflammatory, Antimicrobial, } \\
\text { Anti-tumor }\end{array}$ & Alzheimer's disease, Arthritis \\
\hline Azadirachta indica & $\begin{array}{l}\text { Nimbin, Azadirachtin, gedunin, gallic } \\
\text { acid }\end{array}$ & $\begin{array}{l}\text { Antibacterial, Anti-malarial, Anti-leprotic, Anti- } \\
\text { tuberculosis }\end{array}$ & $\begin{array}{l}\text { To treat skin conditions, dental } \\
\text { tartar and caries, endometritis }\end{array}$ \\
\hline Allium sativum and Allium cepa & Allin, allicin, allyl sulfides & Antibacterial & $\begin{array}{l}\text { MDR pathogens causing } \\
\text { nosocomial infections }\end{array}$ \\
\hline Syzgiuma romaticum & $\begin{array}{l}\text { Eugenol, Eugenol acetate, alpha and } \\
\text { beta caryophyllene }\end{array}$ & $\begin{array}{l}\text { Antibacterial (Food borne pathogens), Anti- } \\
\text { inflammatory, Analgesic }\end{array}$ & Periodontal problems \\
\hline Morinda citrifolia & $\begin{array}{l}\text { Anthraquinones glycosides, Flavanoids, } \\
\text { Iridoids }\end{array}$ & $\begin{array}{l}\text { Anti-inflammatory, Antimicrobial, Anti-oxidant, } \\
\text { Anti-helminthic, Immunomodulating }\end{array}$ & Sickle cell anaemia, Anti-cancer \\
\hline Resveratrol & CIS, Trans forms & $\begin{array}{l}\text { Anti-oxidant, Cardioprotective, Anti-ageing, } \\
\text { Anti-tumour, Immunomodulating }\end{array}$ & Growth promoter \\
\hline
\end{tabular}

Table 1: Different type of herbs, their active constituents, properties and therapeutic uses.

There are number of methods to access the drug interactions:

Checkerboard method.

Time-kill assay.

Diffusion methods (disks, paper strips, E- test, keyhole effect).

\section{Checkerboard assay}

The checkerboard microtiter plate assay is used to test the activities of several drugs in combination against bacteria by determining the FICs of all combinations tested.

\section{Determination of Fractional Inhibitory Concentration (FIC Index)}

The combined effect is analyzed by using measurements of the MIC to calculate the fractional inhibition concentration index (FIC Index) according to the formulas defined by Davidson and Parish [30]:

\section{FIC Index $=$ FICA+FICB}

Where $\mathrm{FICA}=\mathrm{MICA}+\mathrm{B} / \mathrm{MICA}, \mathrm{FICB}=\mathrm{MICB}+\mathrm{A} / \mathrm{MICB}$. The MICA $+B$ value is the MIC of compound $A$ in the presence of compound $B$, and vice versa for MICB+A. Calculating the FIC value (Figures 2 and 3) for either substance A or B then requires determination of the MIC for the individual components. FIC Index results are interpreted as synergistic if FIC Index $<0.5$, additive if $0.5>$ FIC Index $<4$, or antagonistic if FIC Index $>4$ [31]. 
Citation: Bhardwaj M, Singh BR, Sinha DK, Kumar V, Prasanna Vadhana OR, et al. (2016) Potential of Herbal Drug and Antibiotic Combination Therapy: A New Approach to Treat Multidrug Resistant Bacteria. Pharm Anal Acta 7: 523. doi:10.4172/2153-2435.1000523

Page 4 of 14

\section{Time kill assay}

Synergy is defined as showing a $2-\log 10$ decrease in colony count after $24 \mathrm{~h}$ with the combination compared to that with the most active single agent alone, "indifference" as showing less than 2-log10 decrease or some increase in colony count at $24 \mathrm{~h}$ with the combination compared to that with the most active single agent alone and "antagonism" as showing a $2-\log 10$ increase in colony count after $24 \mathrm{~h}$ with the combination compared to that with the most active single agent alone [32]. Time-kill and checkerboard methods are the most widely used techniques to assess synergy but are time-consuming and labor-intensive.

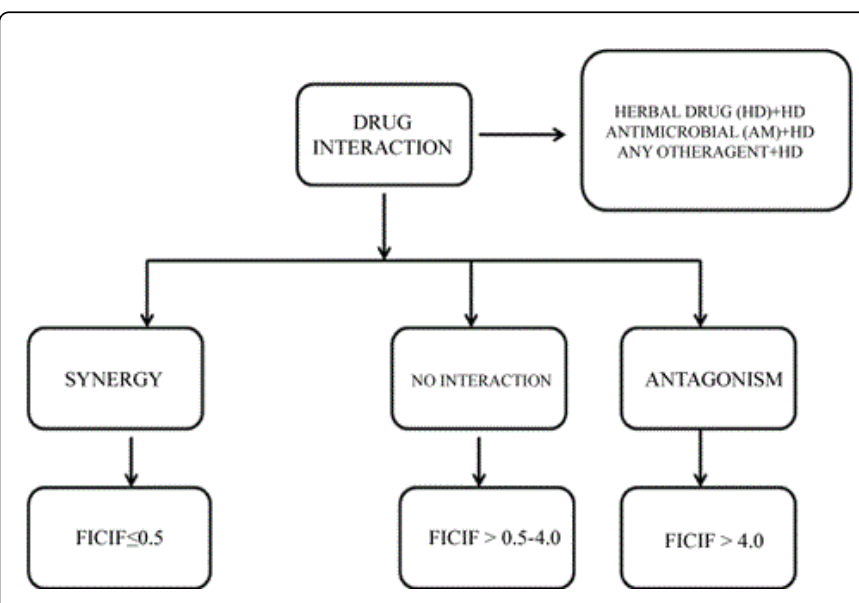

Figure 1: Types of drug interactions.

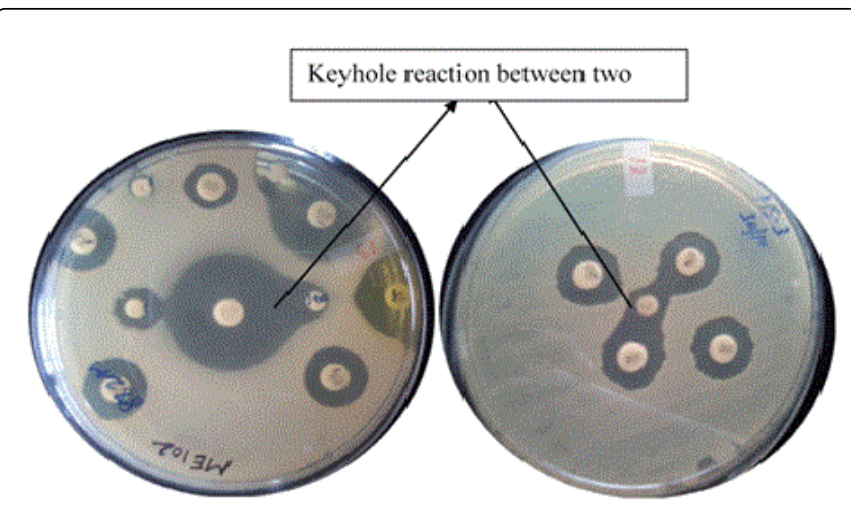

Figure 2: Synergy between two antimicrobials indicated by key-hole formation.

\section{Disc Diffusion Methods}

\section{E-test (Epsilometer test)}

This test is new agar diffusion method for performing antimicrobial susceptibility testing. The E-test strip is placed onto the surface of an agar plate inoculated with bacteria and incubated overnight and an elliptical zone of inhibited growth is formed around the strip. The MIC is read at the intersection of the zone with the strip. This new method of performing synergy tests would represent an attractive alternative to its labor intensive predecessors. White et al. [33] performed synergy testing of Escherichia coli ATCC 35218, Enterobacter cloacae ATCC 23355, Pseudomonas aeruginosa ATCC 27853 and Staphylococcus aureus ATCC 29213 with various combinations of cefepime or ceftazidime with tobramycin or ciprofloxacin using time-kill, checkerboard, and E test techniques. Sopirala et al. [34] compared in vitro susceptibility testing by epsilometric (E test) methods and the checkerboard (CB) method with testing by time-kill analysis for clinically isolated Acinetobacter baumannii strains. They were tested in vitro with tigecycline, colestimethate, imipenem, and amikacin. This study indicates the utility of synergy testing to predict activity of specific antibiotic combinations against pan-drug resistant $A$. baumannii.

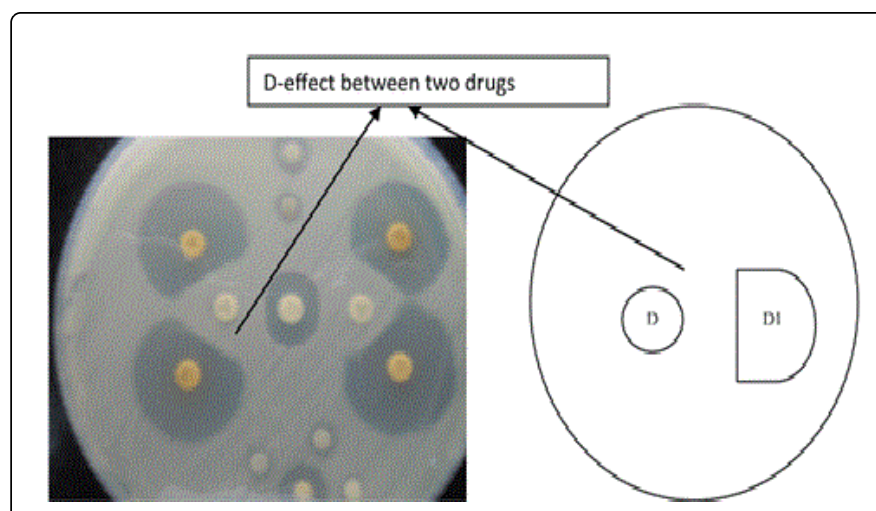

Figure 3: Antagonism between two antimicrobials indicated by Deffect, growth of bacteria resistant to drug $\mathrm{D}$ also show truncation effect on zone of inhibition of drug D1 (to which bacteria have sensitivity) indicated by formation of $\mathrm{D}$.

\section{Keyhole reaction}

The test is also known as double disk synergy test. The test was described by Jarlier and coworkers [35] for detection of ESBL enzymes in E. coli and Klebsiella pneumoniae isolates. In this method, a standardized inoculum of test isolate is swabbed on MHA. An amoxiclav (amoxicillin/clavulanic acid 30/10 $\mu \mathrm{g}$ ) disc is placed at the centre of plate, surrounded by ceftazidime, cefotaxime, ceftriaxone, aztreonam are placed $20-30 \mathrm{~mm}$ away from this central disk. An extension in zone of inhibition around peripheral disks towards central disk indicates ESBL production. This extension is known as 'keyhole reaction. The keyhole reaction can be seen in Figure 2 .

\section{D-effect}

The D-effect can be seen in disk diffusion method between different antibiotics placed in close proximity. The effect is also used to determine some mutations or drug actions so named as D-Test or Double Disk diffusion test. If two antibiotics are tested in close proximity in disc diffusion method, then inducing agent diffuses in media and induces some particular gene expression. This gene expression inhibits the sensitivity zone of another antibiotic in its proximity. Due to this effect, that side of the zone of inhibition is compressed and flattened which forms D-shape zone of inhibition. The ideal distance between antibiotic discs is not properly known but a distance of $15-20 \mathrm{~mm}$ is used in routine testing. Plates are analyzed after $18 \mathrm{~h}$ of incubation at $35^{\circ} \mathrm{C}$. There are chances of false positive as well as false negative results. The effect can be seen in Figure 3 . 
The effect is commonly seen in staphylococcal species. Staphylococcus aureus which is susceptible to Clindamycin but resistant to erythromycin may possess resistance to clindamycin [36]. In the case of clindamycin, resistance to Staphylococcus species can be inducible or constitutive [37]. Staphylococcal strains with inducible resistance to clindamycin appear erythromycin resistant and clindamycin sensitive in disk diffusion method when used far from each other, difficult to detect routinely in a laboratory. The isolates which possess clindamycin resistance with inducible phenotype can undergo a quick in vitro and in vivo conversion to a constitutive resistance phenotype [38].

\section{Synergy among herbal antimicrobials}

The essential oils are widely known for their antimicrobial properties. The essential oil has been indicated for the treatment of conditions like rhinitis, wet coughs, and minor burns and in the emergency treatment of wounds [39]. The aqueous and ethanolic extracts of fruits and leaves (1000 ppm) of Foeniculum vulgare, Priminella anisum, Carum carvi, Majorana hortensis, Mentha longifolia and Salvia officinalis have been tested individually and in combination for their antibacterial activity against drug resistant $E$. coli $\mathrm{O} 157: \mathrm{H7}$ isolates from cattle, human and food. Zone of inhibition of 1.4 and $1.2 \mathrm{~cm}$ for aqueous extracts of Foeniculum vulgare and ethanolic extracts of Salvia officinalis, respectively was observed against E. coli O157:H7 on testing individually. On another hand the combination of aqueous extracts of Foeniculum vulgare, Priminella anisum, and Carum carvi in the ratio of 1:1:1 showed $2.5 \mathrm{~cm}$ Zone of inhibition against $E$. coli. The results showed the synergistic activity of plant extracts against E. coli O157:H7 isolates [40]. The drug interaction can be of different types as we have already discussed. The interaction between different drugs can be shown in graphical form in Figures 4 and 5 .

Lavender oil (Lavandula angustifolia) is one of the commercially available and popular essential oil. The oil is used as antibiotic or antiseptic in combination with other oils like so that it can act synergistically to further enhance these effects (bitter orange, caraway, cedar wood, chamomile, geranium, grapefruit, lemon, marjoram, patchouli, rosemary, sage, sweet orange, and ylang-ylang). They are responsible for healing in a holistic manner by stimulating the mind, body, and senses. Cinnamomum zeylanicumon combination with $L$. angustifolia has been associated with the treatment of topical infections, as a general antimicrobial agent [41]. Lavandula angustifolia was combined with other different 45 oils (in ratio 1:1) to find any possible antimicrobial interactive properties. Most of the interactions were additive (48.9\%) than synergistic (26.7\%) followed by noninteractive $(23.7 \%)$ and antagonistic $(0.7 \%)$. The best interaction was found between $L$. angustifolia with Cinnamomum zeylanicum against Candida albicans and with Citrus sinensis against $S$. aureus, respectively. When placed in various ratios the combination of $L$. angustifolia and $C$. sinensis essential oil demonstrated the best antimicrobial effect with synergy identified for all ratios against the microorganisms tested. The combination has shown a greater antifungal effect when placed in various ratios as five of the nine ratios of different oils against $C$. albicans [42].

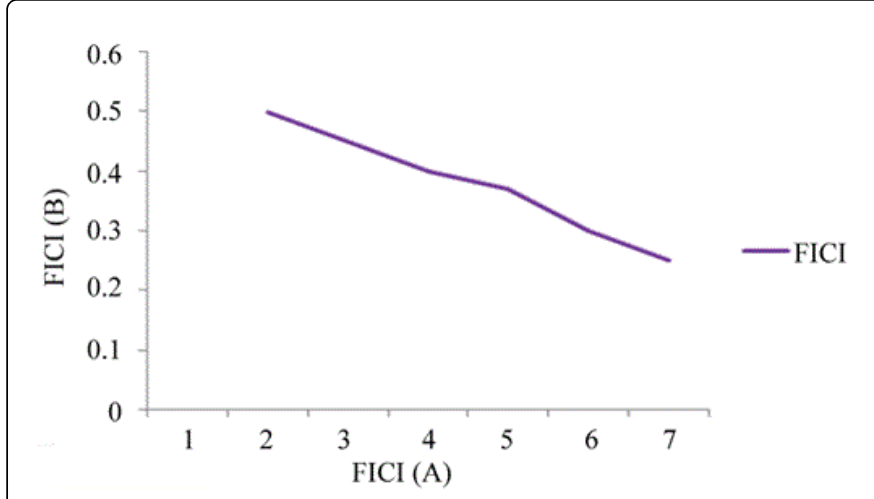

Figure 4: Fractional inhibitory concentration (FIC) showing value less than 0.5 showing synergy.

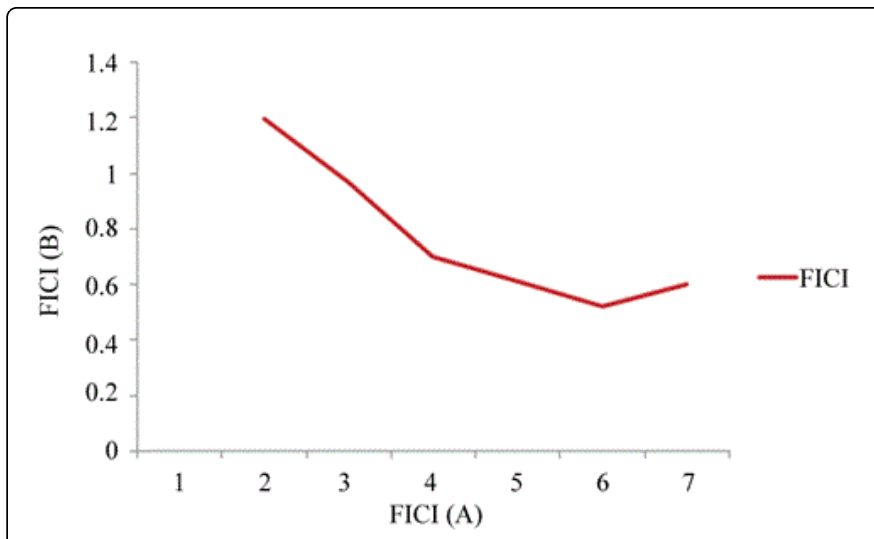

Figure 5: Fractional inhibitory concentration (FIC) showing value more than 0.5 showing antagonism.

Combined therapy is traditionally used to increase antimicrobial activity and reduce toxic effects of agents [43]. Thyme plant is having a property of healing, antiseptic fumigator, food preservation etc. [44]. Thymus vulgaris EO exhibits wide range of antimicrobial activity [45]. Its two main components thymol and carvacrol was demonstrated against Staphylococcus aureus [46], including methicillin-resistant isolates [47] etc. Studies on antibacterial activity of Thymus vulgaris essential oil in combination with other essential oils against $S$. aureus and $E$. coli indicated synergistic effect. The combination of T. vulgaris and Cinnamomum zeylonicum against $S$. aureus had FIC index of 0.26. The essential oils of Juniperus communis and Picea abies EOs showed additive effect (FIC indexes were 0.74 and 0.78 , respectively). Thymus vulgaris in combination with Anibarosaeodora and Melissa officinalis had synergistic antimicrobial effect against E. coli with FIC of 0.23 and 0.34 , respectively, whereas combination of T. vulgaris and Mentha piperita was found additive (FIC index 0.55). The combinations of essential oils are suggested as an effective and economic alternative to treat various infections instead of antibiotics [48].

The carvacrol and p-cymene in combination have been tried on Bacillus cereus. It was suggested that p-cymene induces swelling of bacterial cell membranes that enable easier entry of carvacrol into the cell membrane [49]. García-García et al. [50] found the most 
synergistic binary combination against $L$. innocua to be carvacrol and thymol, and the most active ternary combination to be carvacrol, thymol and eugenol.

Allium sativum (Garlic) belongs to family Liliaceae is a perennial bulb-forming plant. Garlic has been used for dietary and therapeutic purposes [51]. Gongronema latifolium belongs to family Asclepiadaceae. Extracts of Allium sativum (E1) and Gongronema latifolium (E2) when combined against $E$. coli and $S$. aureus had reduced zone of inhibition than induced by anyone them in isolation. Besides, both plant extracts were antagonistic with ciprofloxacin against $E$. coli whereas synergistic against $S$. aureus. The similar additive effect was seen on a combination of Gongronema latifolium and ampicillin against $S$. aureus. They have observed synergism between Allium sativum and ampicillin against $S$. aureus [52]. Similarly, the antibacterial activity of orientin and vicenin flavonoids of Ocimum sanctum had synergistic activity against E. coli, Proteus, $S$. aureus, S. cohni and Klebsiella pneumonia [53].

Ginkgo biloba belongs to division Ginkgo phyta and is used as traditional Chinese Medicine. Ginkgo biloba Leaves contain many kinds of bioactive components like flavonoids, biflavones, proanthocyanidins, alkylphenols, carboxylic acids, sterols, polyprenols etc. [54]. The non-saponifiable lipids of GBL contained terpenoids, polyprenols, sterols, chainlike alcohols. Ginkgo biloba polyphenols is generally composed of 15 to 21 unsaturated isoprene units [55]. The synergistic interactions were evaluated between Ginkgo biloba polyprenols (GBP) and lipids (extracted from Ginkgo biloba leaves) against Salmonella enterica, $S$. aureus and Aspergillus niger. Total eight compounds were extracted from GBL i.e., isophytol, nerolidol, linalool, $\beta$-sitosterol acetate, $\beta$-sitosterol, stigmasterol, ergosterol, $\beta$-sitosterol-3$\mathrm{O}-\beta$-D-glucopyranoside and Ginkgo biloba polyprenols (GBP). The combinations between various components have been tested for synergy. The FIC of 0.25 showed that GBP with isophytol mixture had the strongest synergistic effect against Salmonella enterica among all the three tested strains [56].

The synergistic interactions of honey with curcuma starch were evaluated on $E$. coli and P. aeruginosa. The MIC for the six varieties of honeys ranged between 12 and 18\% (vol/vol) and 11 and 15\% (vol/vol) against $E$. coli and $P$. aeruginosa, respectively in combination. However, MIC of kinds of honey without curcuma starch was $5-70 \%$ (vol/vol) and 5-40 \% (vol/vol) against $E$. coli and $S$. aureus, respectively [57].

\section{Interaction between herbal drugs and antibiotics}

With an increase in antibiotic resistance, the idea of synergy between herbal drugs and antibiotics is a new approach to treating multidrug-resistant bacteria. The combination of two drugs can be synergistic, additive or antagonistic. The effect is said to be synergistic if the effect of the combination is more than it would be if the concentration of the second drug is replaced by the first drug, whereas antagonistic if combined effect will be less than alone effect. Synergy results in increased killing rate, potentiating of drug, prevention of drug elimination, a better effect in vivo etc. Understanding of synergy mechanism may provide a new strategy for the treatment of infectious diseases by reducing the side effects produced by high doses of antibiotics. The herbal extracts and antibiotics are tested for synergistic association against multi-drug resistant bacteria [18].

Various mechanisms of synergy are described such receptor blocking or active site modification [58], enzymatic degradation and modification of the drug [59], accumulation of the antibiotic within the bacterial cell due to decreased outer membrane permeability [60], active efflux [61] etc. The success of combination therapy against various infections has been observed for many years. Due to this, the combination approach has been applied in the treatment of cancer stress-induced insomnia, hypertension, arthritis, AIDS etc. The treatment approach can be single targeted called as "silver bullet" or multitargeted called as "herbal shotgun" [62]. For the treatment of multifactorial diseases, 3-5 drugs can be used together to treat them. Synergistic combinations are composed of antibiotics with EOs of plants [63], antibiotics and bacteriophages [64], antibiotics and nanoscaled metals [65] antibiotics with quorum-sensing inhibitors [66], antipsychotic and anti-inflammatory drugs Lehtinen and Lilius [67] and many more.

Nisin and thymol alone and in combination were tested for antibacterial activity against L. monocytogenes and Bacillus subtilis. It was found that the antibacterial effect of nisin $Z$, produced by Lactococcus lactis was enhanced by sub-inhibitory concentrations of thymol for both strains of bacteria. Moreover, the use of low concentrations of nisin reduces the chances of growth of nisin-resistant bacteria sub-populations [68]. The synergistic antimicrobial activity of tea and antibiotics has also been evaluated against enteropathogens like Salmonella Typhimurium1402/84, S. Typhi, S. Typhi Ty2a, Shigella dysenteriae, Yersinia enterocolitica C770, and E. coli (EPEC P2 1265). A combination of chloramphenicol and tea extract inhibited the growth of $S$. dysenteriae at the chloramphenicol concentration of 2.5 $\mu \mathrm{g} / \mathrm{ml}(\mathrm{MIC} 5 \mu \mathrm{g} / \mathrm{ml}$ ) and $5.094 \mathrm{mg} / \mathrm{ml}$ black-tea extracts (MIC 9.089 $\mathrm{mg} / \mathrm{ml}$ ). Tea extract also showed synergistic activity with other antibiotics like gentamicin, methicillin and nalidixic acid [69].

The biofilm inhibitors, acetic acid and corosolic acid evaluated for effect on $P$. aeruginosa biofilms growth in rotating disk reactors in combination with antibiotics tobramycin and ciprofloxacin revealed selective synergy. A non-mucoid strain of $P$. aeruginosa formed biofilm tolerating ciprofloxacin but could not in presence of both the acids without affecting the viable cell density of $P$. aeruginosa. Both compounds potentiated the activity of antibiotic tobramycin against biofilm bacteria [70]. The crude extract from Salvia officinalis containing carnosol reduced the MIC of aminoglycosides in vancomycin-resistant enterococci (VRE). Similar compound carnosic acid had synergistic effect with gentamicin too [71].

The in vitro antibacterial activity of kaempferol against antibioticresistant Propionibacterium acnes alone and in combination with erythromycin and clindamycin was tested. The combination effect analyzed by checkerboard test revealed MICs for both compounds were $\leq 32 \mu \mathrm{g} / \mathrm{ml}$ for clindamycin-sensitive strains and $\geq 64 \mu \mathrm{g} / \mathrm{ml}$ for clindamycin resistant $P$. acnes strains. A combination of kaempferol with quercetin showed an indifferent effect whereas a combination of clindamycin with kaempferol or quercetin showed a greater synergistic effect than that of erythromycin with kaempferol or quercetin [72]. The essential oil of Helichrysum italicum reduced the multidrug resistance of different bacteria like Enterobacter aerogenes, E. coli, $P$. aeruginosa and Acinetobacter baumannii. Geraniol significantly increases the efficacy of beta-lactams, quinolones, and chloramphenicol [63]. It is observed that at $40 \mathrm{mM}$, ellagic and tannic acids enhanced the activity of novobiocin, coumermycin, clorobiocin, rifampicin and fusidic acid against $A$. baumannii [73].

Salvia officinalis (sage) is an aromatic plant belongs to family Lamiaceae and used as flavoring agent in a number of foods. Its main constituents are diterpenoids, triterpenoids, flavonoids and phenolic 
glycosides. It was found that Salvia is strongly antioxidant and strong use of Salvia tea for 14 days has improved liver antioxidant status [74]. Studies on antibacterial activity of aqueous extracts of Salvia officinalis alone and with the preservatives like sodium nitrite, sodium benzoate and potassium sorbate against some of the food spoiling bacteria have shown synergistic antimicrobial action against Agrobacterium tumefaciens, Bacillus subtilis and Proteus sp. The synergism was accessed by using checkerboard method. Synergism was observed up to $1 / 8$ MIC values. The FIC index was varied from $0.25-0.50$. Around $33.3 \%$ bacterial species have shown synergy for the combination of aqueous extract and sodium benzoate. Also, 33.3\% of bacteria have shown indifference and additive effect. The combination of aqueous extract and potassium sorbate exhibits additive effect against $66.6 \%$ of bacterial species, indifferent effect against $22.2 \%$ bacteria whereas single isolate was showing synergy. Sodium nitrite combination with Salvia sp. extract exerted synergistic effect on $55.5 \%$ of bacteria and $33.3 \%$ showed indifference in effect. The study concluded utility of combination as a natural preservative in food [75]. Ge et al. [76] found the synergy of Oleanolic Acid (OA), a triterpenoid, with isoniazid, rifampicin or ethambutol anti-mycobacterial effects against drugresistant strains of $M$. tuberculosis with FICs of 0.121-0.347, $0.113-0.168$ and $0.093-0.266$, respectively.

The in vitro antimicrobial effects of different spices and herbs namely, Piper nigrum, Coriandrum sativum, Cuminum cyminum, Mentha piperita and Rosmarinus officinalis (Rosemary) against different bacteria and fungi species was studied. The possible effects between herbs and antibiotics were also studied. Standard antibiotic such as gentamicin $(10 \mathrm{Cg})$, amoxicillin/clavulanic acid (20/10) (30 $\mu \mathrm{g})$, erythromycin $(15 \mu \mathrm{g})$, norfloxacin $(10 \mu \mathrm{g})$ discs were used for comparison with the antimicrobial activities of essential oils of these plants. The study was carried on Micrococcusluteus, Bacillus cereus, Salmonella typhimurium, Listeria monocytogens, Escherichia coli, Lactobacillus acidophilus, Staphylococcus aureus, Streptococcus pneumoniae and Candida albicans. A synergistic effect was seen in all microorganisms when combination of Piper nigrum essential oil $(2 \mu \mathrm{l})$ and gentamicin antibiotic discs was used. In the case of Listeria monocytogens and Lactobacillus acidophilus additive effect was seen. A synergistic effect was seen highest against bacteria Listeria monocytogens, Salmonella Typhimurium and Lactobacillus acidophilus. The additive effect was observed in $S$. aureus on combining $C$. sativum essential oil $(2 \mu \mathrm{l})$ and gentamicin antibiotic discs whereas an antagonistic effect was seen in a combination of $C$. sativum essential oil $(2 \mu \mathrm{l})$ and erythromycin antibiotic discs in all tested bacteria [77].

A member from family Piperaceae, Piper species have a number of biologically active natural products, such as pyrenes, lignans, neolignans, terpenes, propenylphenols, chalcones, flavones, benzopyrenes, chromenes, lactones, and amides [78]. The antimicrobial activity and synergism of Piper gaudichaudianum Kuntze with different antibiotics were studied. The crude extract, fraction F2 (dichloromethane-ethyl acetate 95:5), and fraction F3 (dichloromethane-ethyl acetate 50:50) showed good activity against Staphylococcus aureus, Bacillus subtilis, and Candida tropicalis and showed synergism with ceftriaxone, tetracycline, and vancomycin. The synergism was accessed by isobologram and checkerboard method. Morphological changes in form and structure were found by scanning electron microscopy in $S$. aureus treated with the combination of fraction F2 and vancomycin [79]. Bharti and Vasudeva [15] evaluated the antimicrobial activity of Oreganum vulgareessential oil and phenolic and non-phenolic fractions of chloroform extract alone and in combination with ciprofloxacin against $S$. aureus and with fluconazole against $A$. terreus. The volatile oil and the phenolic fraction of chloroform extract have shown synergistic antibiotic and antifungal effects.

The synergistic activity between Salvia officinalis and Cichorium intybus extracts and commonly used antibiotics like amoxicillin and chloramphenicol against bacteria $S$. aureus, E. coli, $P$. aeruginosa, Bacillussubtilis, Enterobacter cloacae, Klebsiella pneumoniae and Proteus mirabilis has been reported. Salvia officinalis extract was found more synergistic than Cichoriumin tybus to enhance the antimicrobial activity of both the antibiotics. Synergistic interactions were observed between ethyl acetate extract of Salvia officinalis with amoxicillin and chloramphenicol. At the sub-inhibitory concentration (1/4-1/32 MIC) of Salvia officinalis extracts, the MIC values of antibiotics were decreased by 2-10 fold. The combinations of Cichoriumin tybus acetone and ethyl acetate extract with antibiotics showed either additive or indifferent effects. The study concluded that synergistic activity of extracts of $S$. officinalis and some of the tested antibiotics can be an alternative treatment method [80].

The interaction between ampicillin and polyphenol theaflavin against Stenotrophomonas multophilia isolates was determined by using checkerboard assay. It was found that MIC of ampicillin was reduced from $12.5-22.9 \mu \mathrm{g} / \mathrm{mL}$ to $3.125-6.25 \mu \mathrm{g} / \mathrm{mL}$ when used in combination [81]. FIC index was calculated as $0.22-0.35$ confirms synergy. In continuation, enhancement of antibiotic efficacy of antibiotic combinations with antimicrobials derived from plants, metal ions and nanoparticles and bacteriophage lytic enzymes has been described [82]. Studies in Iran indicated that the combination of antibiotic with oil possessing antimicrobial potential could possibility result in a reduction in the amount of antibiotics to be used [83]

Researchers examined aquo-ethanolic extract of Camellia sinensis standardized using FTIR analysis. Seven common functional groups were found in comparison with marker compound, quercetin. The extract was tested in combination with third line antibiotics (tigecycline, ertapenem, meropenem, colistin, and augmentin) against carbapenem resistant $E$. coli. The FIC was calculated to be less than one. The combination of aqua-ethanolic extract of Camellia sinensis with ertapenem or meropenem showed maximum augmentative potential at $50 \mu \mathrm{g} / \mathrm{mL}$ and $100 \mu \mathrm{g} / \mathrm{mL}$, respectively, with 5 fold decrease in MICs [84]. Bioenhancers are combined with antibiotics like tetracycline combined with drug loperamide to enhance the bioavailability and efficacy of drug by increasing its permeability, without its own pharmacological activity $[85,86]$. Also, Cow Urine Distillate (CUD) enhances rifampicin activity against $E$. coli by 57 times as well as against gram positive bacteria by 311 times [85]. Some of the drug interaction examples will be shown in Table 2 . 
Citation: Bhardwaj M, Singh BR, Sinha DK, Kumar V, Prasanna Vadhana OR, et al. (2016) Potential of Herbal Drug and Antibiotic Combination Therapy: A New Approach to Treat Multidrug Resistant Bacteria. Pharm Anal Acta 7: 523. doi:10.4172/2153-2435.1000523

Page 8 of 14

\begin{tabular}{|c|c|c|c|}
\hline Herbal Drug+Herbal Drug/Antibiotic/any other & Tested against & Type of Interaction & Reference \\
\hline $\begin{array}{l}\text { Foeniculum vulgare, Priminella anisum and Carum } \\
\text { carvi }\end{array}$ & Escherichia coli & Synergistic & {$[40]$} \\
\hline L. angustifolia+Cinnamomum zeylanicum & Candida albicans & Synergistic & - \\
\hline L. angustifolia+Citrus sinensis & Staphylococcus aureus & Synergistic & [42] \\
\hline L. officinalis and M. alternifolia & \multirow[t]{2}{*}{ Methicillin resistant S. aureus (MRSA) } & Antagonism & [42] \\
\hline Cymbopogon citratus and $L$. angustifolia & & Antagonism & [42] \\
\hline T. vulgaris and Cinnamomum zeylonicum & S. aureus & Synergistic & [48] \\
\hline T. vulgaris and Mentha piperita & E. coli & additive & [48] \\
\hline Carvacrol and thymol & Listeria innocua & Synergistic & {$[50]$} \\
\hline Orientin and vicenin flavanoids of Ocimum sanctum & $\begin{array}{l}\text { E. coli, Proteus, S. aureus, S. cohni and } \\
\text { Klebsialla pneumoniae }\end{array}$ & Synergistic & {$[103]$} \\
\hline $\begin{array}{l}\text { Ginkgo biloba polyprenols (GBP) and lipids } \\
\text { (extracted from Ginkgo biloba leaves) }\end{array}$ & $\begin{array}{l}\text { Salmonella enterica, S. aureus and } \\
\text { Aspergillus niger }\end{array}$ & Synergistic & {$[56]$} \\
\hline Honey with curcuma starch & E. coli and Pseudomonas aeruginosa & Synergistic & {$[57]$} \\
\hline Chloramphenical and tea extract & Shigella dysenteriae & Synergistic & {$[69]$} \\
\hline Kaempferol with quercetin & Propionibacterium acnes & Indifference & {$[72]$} \\
\hline $\begin{array}{l}\text { Ellagic and tannic acids+novobiocin, coumermycin, } \\
\text { clorobiocin, rifampicin and fusidic acid }\end{array}$ & Acinetobacter baumannii & Synergistic & [73] \\
\hline C. sativum essential oil $(2 \mu \mathrm{l})$ and Erythromycin & $\begin{array}{l}\text { Micrococcus luteus, Bacillus cereus, } \\
\text { Salmonella Typhimurium, Listeria } \\
\text { monocytogens, E. coli, Lactobacillus } \\
\text { acidophilus, S. aureus, Streptococcus } \\
\text { pneumoniae and C. albicans. }\end{array}$ & Antagonism & {$[77]$} \\
\hline $\begin{array}{l}\text { Salvia officinalis and Cichoriumin tybus extracts and } \\
\text { commonly used antibiotics like amoxicillin and } \\
\text { chloramphenicol }\end{array}$ & $\begin{array}{l}\text { S. aureus, E. coli, P. aeruginosa, Bacillus } \\
\text { subtilis, Enterobacter cloacae, K. } \\
\text { pneumoniae and Proteus mirabilis }\end{array}$ & Synergistic & [80] \\
\hline Camellia sinensis+ertapenem, meropenem & Carbapenem resistant $E$. coli & Synergistic & {$[84]$} \\
\hline Cinnamon and other herbal drugs & $\begin{array}{l}\text { L. monocytogenes, B. cereus and Yersinia } \\
\text { enterocolitica }\end{array}$ & Synergistic & {$[108]$} \\
\hline Cinnamon and other herbal drugs & E. coli & Antagonism & {$[108]$} \\
\hline $\begin{array}{l}\text { Oreganum vulgare essential oil and phenolic and } \\
\text { non-phenolic fractions of chloroform extract in } \\
\text { combination with ciprofloxacin }\end{array}$ & S. aureus & Synergistic & [15] \\
\hline $\begin{array}{l}\text { Oreganum vulgare essential oil and phenolic and } \\
\text { non-phenolic fractions of chloroform extract in } \\
\text { combination with fluconazole }\end{array}$ & Aspergillus terreus & Synergistic & [15] \\
\hline Imipenem and trans-cinnamaldehyde & E. coli & Synergistic & {$[27]$} \\
\hline
\end{tabular}

Table 2: Herbal drugs showing interaction with other agents.

\section{Interaction between Cinnamon and Other Antimicrobials}

\section{Cinnamon and its properties}

Cinnamomum zeylanicum is one of the oldest herbal medicines known, which is mentioned in Chinese texts since 4000 years ago [87]. Cinnamomum zeylanicum is natural spice and remedy to combat bacterial infection, belongs to family Lauraceae [28,66]. The plant is native to Sri Lanka, South East India, Indonesia, South America and West Indies. The active components of the cinnamon oil are cinnamaldehyde [88], ethyl cinnamate, eugenol, $\beta$-caryophyllene, and linalool and methyl chavicol [89]. The cinnamon oil is rich in transcinnamaldehyde with antimicrobial effects against animal and plant pathogens, food poisoning and spoilage bacteria and fungi $[90,91]$. Cinnamon barks and leaves are used as flavoring agent in foods and also for the medicinal purpose [92]. It plays an important role in pharmacological effects such as anti-inflammatory, antimicrobial, antioxidant, anti-diabetes, antispasmodic, antiulcer and cytotoxic properties [93]. It possesses antimicrobial activity also against protozoans [94] and viruses, with minimal mammalian toxicity [95]. The EO of cinnamon has been found to be the most effective antimicrobial, followed by the essential oil of oregano and thyme [96]. 


\section{Mechanism of action}

The antimicrobial activity of cinnamon is due to the presence of aromatic aldehyde i.e., cinnamaldehyde that inhibits amino acid decarboxylase activity [97]. It is active against many pathogenic bacteria [98]. Cinnamaldehyde is highly electro-negative that interferes in biological processes like electron transfer and reacts with nitrogencontaining components, e.g., proteins and nucleic acids. The aldehyde groups of cinnamaldehydeare reactive and have the ability to cross-link covalently with DNA and proteins through amine groups, thereby interfering with their normal function [99]. At low concentrations, cinnamaldehyde inhibits different enzymes involved in cytokinesis. At higher, sub-lethal concentrations, it acts as an ATPase inhibitor and at lethal concentrations it disturbs cell membrane. According to Kwon et al. [100] cinnamaldehyde inhibited cytokinesis in Bacillus cereus by inhibiting the septum formation. It has been established that cinnamaldehyde binds to the FtsZ protein, inhibiting its GTPdependent polymerization and thereby preventing cell division [101]. Besides, enzymes like histidine decarboxylase are also inhibited by cinnamaldehyde [97].

\section{Cinnamon: Antimicrobial action}

Helander et al. [102] reported the inhibition of E. coli O157:H7 and $S$. Typhimurium by the essential oil of cinnamon. Friedman et al. [89] found essential oil of cinnamon active against Campylobacter jejuni and E. coli. Ali et al. [103] observed $3.5 \log$ reduction of $E$. coli O157:H7 in broth containing $1 \mathrm{ppm}$ cinnamaldehyde after $75 \mathrm{~min}$. Yossa et al. [104] observed that cinnamaldehyde exhibits strong antimicrobial properties on E. coli $\mathrm{O} 157: \mathrm{H7}$ and Salmonella. Antibacterial activity of essential oil of cinnamon was maximum against Staphylococcus aureus [105] followed by E. coli and Campylobacter jejuni [106].

\section{Cinnamon and other antimicrobials}

The combined effect of essential oils of cinnamon bark, lavender, marjoram, tea tree, peppermint and ampicillin, piperacillin, cefazolin, cefuroxime, carbenicillin, ceftazidime, meropenem, analyzed by checkerboard method against beta-lactamase-producing $E$. coli indicated useful synergy. Two to four-fold reductions in MIC of the antibiotics was noted. Piperacillin+cinnamon and piperacillin +lavender FIC indices were 0.5 and 0.38 , respectively [107]. The effect of combination of cinnamon and other herbal drugs was also observed on E. coli, Yersinia enterocolitica, P. aeruoginosa and Salmonella choleraesuis, S. aureus, Listeria monocytogenes, Bacillus cereus and Enterococcus faecalis. The combination of two showed a synergistic effect for inhibiting the growth of L. monocytogenes, B. cereus, and $Y$. enterocolitica whereas antagonism was observed when tested against E. coli [108]. Recently, the synergy between imipenem and transcinnamaldehyde has been reported in the study on 168 E. coli isolates, 42 (25\%) revealed synergy [27].

Studies on combination of cinnamon oil, thyme oil, nigella extract and clove extract with imipenem against $S$. aureus $5 \mathrm{~S}$ and $P$. aeruginosa $30 \mathrm{~S}$ revealed a significant increase in growth inhibition zones indicating synergy. In the case of $S$. aureus $5 \mathrm{~S}$, combination between imipenem and cinnamon oil (MIC) decreased the MIC value of imipenem from $62.5-12.5 \mu \mathrm{g} / \mathrm{ml}$. In the case of $E$. coli, a combination between imipenem and cinnamon oil (MIC) decreased the MIC value of imipenem from 15.625-6.25 $\mu \mathrm{g} / \mathrm{mL}$ [109].

\section{Carvacrol in Combination with Other Antimicrobials}

\section{Carvacrol and its properties}

Carvacrol [2-methyl-5-(methylethyl) phenol] is one of the major components of oregano oil which is known for a wide spectrum of antimicrobial activity in vitro or in vivo $[110,111]$. Carvacrol is a wellknown constituent of some medicinal plants, like black cumin (Nigella sativa), oregano (Origanum compactum), Monarda didyma, Origanum dictamnus, Origanum microphyllum, Origanum onites, Origanum scabrum, Origanum vulgare, thyme (Thymus glandulosus), savory (Satureja hortensis) [112]. The percent composition of carvacrol in oregano ranges from trace amounts to $82 \%$ and $2-45 \%$ in thyme. Carvacrol [2-methyl-5-(1-methylethyl) phenol] is biosythensized from p-cymene and g-terpinene [113]. The hydrophobic phenolic compound in its structure is thought to be the main contributor to its antimicrobial properties; however, other components of its structure may also be important in this regard [114]. Carvacrol possesses multiple biological properties such as anti-inflammatory, antileishmanial, antioxidant, hepatoprotective, antimicrobial, antitussive, antispasmodic and anti-tumoral activities [115].

Carvacrol is considered safe for consumption and has been approved by the federal drug administration for addition in food. Similarly, the council of Europe included carvacrol in the list of chemical flavorings that can be found in alcoholic beverages, baked goods, chewing gum, In food industry, carvacrol is added to different products, e.g., baked goods (15.75 ppm), nonalcoholic beverages (28.54 $\mathrm{ppm} / 0.18 \mathrm{mM})$, chewing gum (8.42 ppm) [116].

\section{Mechanism of action}

The effectiveness of carvacrol as a natural antimicrobial is well established; however, the mechanism of action is less understood and is believed to be associated with damage to the cell membrane. The phenolic component of carvacrol has prompted research focused on its effect on structural and functional damage to cellular membranes [117]. Permeability of the cell membrane is dependent on the hydrophobicity and the composition of the solutes that have to cross the membrane [118].

According to Lambert et al. [26] the possible mode of action of carvacrol is by disintegrating the outer membrane of bacterial cells. The underlying mechanism of carvacrol induced inhibition of growth of both Gram-positive and Gram-negative bacteria by similar to that of other phenolic compounds and occurs via membrane damage resulting in an increase in membrane permeability and disruption of the cell wall. Helander et al., [102] also reported a similar mechanism for carvacrol by releasing lipopolysaccharides (LPS) thereby increasing the permeability of the cytoplasmic membrane to ATP. However, +, 1997, opined that carvacrol act through disruption of proton motive force (PMF), electron flow, active transport and coagulation of cell contents.

\section{Carvacrol: Antimicrobial action}

Carvacrol exerts a broad spectrum of antimicrobial activity against both Gram-positive and Gram-negative bacteria isolated from food and clinical isolates and showed that it exerts bacteriostatic and bactericidal activities against Vibrio cholerae, Campylobacter jejuni, Escherichia coli, Listeria monocytogenes, Salmonella enteric serovar Typhimurium, Staphylococcus aureus, Staphylococcus epidermidis, Lactobacillus sakei, Pseudomonas aeruginosa, Pseudomonas putida, 
Streptococcus mutans, and Bacillus subtilis [118]. Botelho et al., [119] reported its antifungal activity against Candida albicans. Nostro et al. [110], proved it effective even against meticillin-resistant strains of Staphylococcus aureus and Staphylococcus epidermidis.

Several studies have proved that carvacrol has both bacteriostatic and bactericidal activity against microorganisms such as Escherichia coli O157:H7 [119,120], Pseudomonas fluorescens [121] etc.

\section{Carvacrol and other antimicrobials}

Carvacrol has been combined with other preservatives or preservative methods to control foodborne microorganisms. It has been shown to have stronger antimicrobial effect with increased temperature and storage time, and at a lower $\mathrm{pH}$ [122]. Some antimicrobials that have been combined with carvacrol to control foodborne microorganisms include p-cymene [123], nisin [124], thymol [28], eugenol [28], citral [125], cinnamaldehyde [126] and EDTA [127]. Encapsulated carvacrol in surfactant micelles has been proven effective in inhibiting the growth of Escherichia coli O157:H7 and Listeria monocytogenes [120]. Karatzas et al., [128] reported that carvacrol and high hydrostatic pressure (HPP) acted synergistically in inactivating Listeria monocytogenes. The combinations of Origanum vulgare $\mathrm{EO}$ and different antibiotics against a MDR strain of extendedspectrum $\beta$-lactamase-producing E. coli was examined [129] and a combination of whole oregano oil with penicillin had no synergistic antimicrobial effect against $E$. coli $[129,130]$. However, the synergistic activity of thymol and carvacrol with penicillin against $E$. coli and $S$. Typhimurium has been reported [131].

\section{Herbal drugs and antibiotics in combination: as therapeutics in vivo}

Mostly the studies of drug interaction are carried out in vitro. But in human medicine, some of the studies are carried out in vivo to determine effect of combined therapy. The anticancer drugs like Polyphyllin I (rhizome of Parispolyphyllin) and evodiamine (Evodiarutae carpa) are less effective individually as compared to other anticancer drugs but on combination, they are significantly more effective in cancer patients. The CI values were $<1$ in all combinations at fraction affected $(\mathrm{Fa})=80 \%$, indicating a synergistic anti-cancer effect [132]. Salvia Miltiorrhiza, Panax Notoginseng and Borneol in combination proved to be more effective in case of cardiovascular diseases [133]. In case of hepatic injury syndrome, Artemisia annua L. Gardenia jasminoids Ellis, and Rheum palmatum L. exhibit more strong therapeutic effect as compared to individual effect by targeting multiple sites in rat hepatic injury [134]. During the year 2012-2013, in cattle farm of IVRI, Izatnagar, screening of diarrhoeic calves was done to identify pathogenic bacteria. The calves were treated with three different combinations that included group 1 (antibiotics), group II (antibiotic+herbal drug) and group III (herbal drugs). In test group-I diarrhoeic calves received gentamicin $(4 \mathrm{mg} / \mathrm{kg}$ body weight) intramuscular twice daily for 3-5 days. Test group-II diarrhoeic calves received gentamicin ( $4 \mathrm{mg} / \mathrm{kg}$ body weight) intramuscular twice daily and herbal extracts i.e., ethanolic extract of Holarrhena antidysenterica (bark) $(10 \mathrm{mg} / \mathrm{kg}$ body weight)+leaves of Dalbergia sissoo $(10 \mathrm{mg} / \mathrm{kg}$ body weight) orally twice daily for 3-5 days. Test group-III diarrhoeic calves received herbal extracts- $H$. antidysenterica (10 mg/kg body weight) and leaves of D. sissoo (10 $\mathrm{mg} / \mathrm{kg}$ body weight) orally twice daily for 3-5 days. The combined therapy (in group II) had a profound effect on biochemical profile of diarrhoeic calves, the altered values as recorded on day 0 in respect of number of parameters viz. PCV, TSP, serum creatinine, serum albumin, serum urea nitrogen and serum potassium come towards normal values by day 7 post therapy. As regards to haemoglobin SGOT, SGPT, A:G ratio and serum gamma globulin in group II diarrhoeic calves values recorded before treatment were in the normal range for the species and these values did not change significantly consequent to muscular gentamicin and oral herbal therapy on Day 7 of post treatment. So, the combined therapy being more useful over individual therapy was advocated in clinical management of diarrhea in calves [135].

\section{Conclusion}

Herbal drugs have great potential as an antimicrobial agent. In combination with each other or with other antimicrobial agents they may of immense value in decreasing use of antibiotics. The synergistic effects between herbal drugs and antibiotics against resistant bacteria provide a new and alternative way of treatment of resistant microbes. The synergistic action is of more importance in case where antibiotic(s) is no longer effective as a therapeutic agent. Combinations of herbal drugs in form of essential oils provide an effective and economical way in combating antibiotic-resistant bacteria. The analysis of a combination of herbal drugs with other aroma-therapeutic essential oils has largely demonstrated against the pathogens tested. Their FIC indexes have indicated that the essential oils have favourable antimicrobial interactions. The essential oils in combination demonstrate the best antimicrobial effect with synergy identified with all ratios against the microorganisms can be the alternative therapy.

The combinations of essential oils have not been well investigated, so further studies are required to evaluate the effect of herbal drugs in combination. The combination therapies increase the treatment options and reuse of antibiotics in a case where resistance has developed. The use of antibiotics producing side effects can be made by reduced dose exploiting their synergy with herbal antimicrobials. Moreover, to determine whether the drugs were showing synergism or antagonism, it is important to know the molecular mechanism of the antibiotic in presence as well as an absence of herbal drugs for further selection of herbal drugs. On the other hand, with benefits always there are some disadvantages also. The herbal drugs like ginseng saponins are very costly and require 4-6 years to purify it. The methods of extraction and preparation of crude extracts, their purification process influence the inhibition activity of herbal drugs. There is still scope for exploring the problems like stability, selectivity, and bioavailability of the herbal drugs and any of the side effects that may be possible during combined use. The review opens a window to look at the significant potential for the development of novel antimicrobial combinations of antibiotics and herbal antimicrobials. It may be an alternative method for the treatment of several diseases caused by multidrug-resistant bacteria.

\section{References}

1. Abascal K, Yarnell E (2004) Herbs and drug resistance: Potential of botanical in drug-resistant microbes. Altern Complement Ther 1 : 237-241.

2. Singh BR, Singh AK, Sharma S, Reyaz M, Kumar S, et al. (2014) Testing of FMD Vaccine (intended to be used under FMD-CP of Govt of India) at CCS NIAH, Baghpat (UP) India.

3. Gundidza M (1993) Antifungal activity of essential oil from Artemisia afra Jacq. Cent Afr J Med 39: 140-142. 
4. Bidlack WR, Omaye ST, Meskin MS, Topham DKW (2000) Phytochemicals as bioactive agents. CRC press, Boca Raton, FL, USA.

5. Giamperi L, Fraternale D, Ricci D (2002) The in vitro action of essential oils on different organisms. J Essential Oil Res 14: 312-318.

6. Girouard YC, Maclean IW, Ronald AR, Albritton WL (1981) Synergistic Antibacterial Activity of Clavulanic Acid and Amoxicillin Against f8Lactamase-Producing Strains of Haemophilus ducreyi. Antimicrob Agents Chemother 20: 144-145.

7. Chin NX, Neu NM, Neu HC (1986) Synergy of sulbactam and ampicillin against methicillin-resistant staphylococci. Drugs Exp Clin Res 12: 939-42.

8. Jung R, Husain M, Choi MK, Fish DN (2004) Synergistic activities of moxifloxacin combined with piperacillin-tazobactam or cefepime against Klebsiella pneumoniae, Enterobacter cloacae, and Acinetobacter baumannii clinical isolates. Antimicrob Agents Chemother 48:1055-1057.

9. Levinson W, Jawetz E (2002) Medical microbiology and immunology: Examination and board review (7th edn.) Lange Medical Books/ McGraw-Hill, New York.

10. Singh M, Khatoon S, Singh S, Kumar V, Rawat AKS, et al. (2010) Antimicrobial screening of ethnobotanically important stem bark of medicinal plants. Pharmacognosy Res 2: 254.

11. Kumar S, Singh BR (2013) An overview of mechanisms and emergence of antimicrobials drug resistance. Adv Anim Vet Sci 1:7-14.

12. Dhama K, Tiwari R, Chakraborty S, Saminathan M, Kumar A, et al. (2014) Evidence based antibacterial potentials of medicinal plants and herbs countering bacterial pathogens especially in the era of emerging drug resistance: An integrated update. Int J Pharmacol 10: 1-43.

13. Rahal A, Mahim Verma AK, Kumar A (2014) Tiwari, R. Phytonutrient and nutraceuticals in vegetables and their multi-dimensional and health benefits for humans and their companion animals: A review. J Biol Sci 14: 1-19.

14. Akande IS, Ebuehi OA, Samuel TA, Onubogu IC, Esin H (2010) Effects of herbal remedies (Agyanom mixture, Bolex bitters and Remedia mixture) on hepatic and renal functions in male rats. Nig Q J Hosp Med 20: 70-76.

15. Bharti V, Vasudeva $\mathrm{N}$ (2013) In vitro synergistic/ antagonisticantimicrobial effect of culinary herb Oreganum vulgare with antibiotic and antifungal agents. J Herbs Spices Med Plants 19: 207-215.

16. Santos PRV, Oliveira ACX, Tomassini TCB (1995) Control microbiogicode productos. Fitoterapicos. Rev Farm Bioquim 31: 35-38.

17. Ellof JN (1998) Which extractant should be used for the screening and isolation of antimicrobial components from plants? J Ethnopharmacol 60: $1-6$.

18. Nascimento GGF, Locatelli J, Freitas PC, Silv GL (2000) Antibacterial activity of plant extracts and phytochemicals on antibiotic-resistant bacteria. Braz J Microbiol 31: 247-256

19. Mothana RAA, Gruenert R, Bernarski PJ, Lindequist U (2009) Evaluation of the in vitro anticancer, antimicrobial and antioxidant activities of some Yemeni plants used in folk medicine. Pharmazie 64: 260-268.

20. Vadhana P, Singh BR, Bhardwaj M, Singh SV (2015) Emergence of Herbal Antimicrobial Drug Resistance in Clinical Bacterial Isolates. Pharm Anal Acta 6: 10.

21. Bakkali F, Averbeck S, Averbeck D, Idaomar M (2008) Biological effects of essential oils-A review. Food Chem Toxicol 46: 446-475.

22. Burt S (2004) Essential oils: Their antimicrobial properties and potential applications in foods: A review. Int J Food Microbiol 94: 223-253.

23. Inouye S, Yamaguchi H, Takizawa $T$ (2001) Screening of the antibacterial effects of a variety of essential oils on respiratory tract pathogens, using a modified dilution assay method. J Inf Chemother 7: 251-254.

24. Griffin GS, Wyllie GS, Markham LJ, Leach DN (1999) The role of structure and molecular properties of terpenoids in determining their antimicrobial activity. Flavour Fragr J 14: 322-332.

25. Nostro A, Cannatelli MA, Musolino AD, Procopio F, Alonzo V (2002) Helichrysumitalicum extract interferes with the production of enterotoxins by Staphylococcus aureus. J Appl Microbiol 35:181-184.
26. Lambert RJW, Skandamis PN, Coote PJ, Nychas GJ (2001) A study of the minimum inhibitory concentration and mode of action of oregano essential oil, thymol and carvacrol. J App Microbiol 91: 453-462.

27. Bhardwaj M, Singh BR, Sinha DK, Kumar VOR, Vadhana P, et al. (2016) Synergistic antimicrobial activity of trans-cinnamaldehyde with imipenem on Escherichia coli. Proceedings of XXIX Annaula Convention of IAVMI, Guwahati, p: 166

28. Pei RS, Zhou F, Ji P, Xu J (2009) Evaluation of Combined Antibacterial Effects of Eugenol, Cinnamaldehyde, Thymol and Carvacrol against $E$. coli with an Improved Method. J Food Sci 74: 379-383.

29. Bassole IHN, Juliani HR (2012) Essential oils in combination and their antimicrobial properties. Molecules 17: 3989-4006.

30. Davidson PM, Parish ME (1989) Methods for testing the efficacy of food antimicrobials. Food Technol 43: 148-155.

31. Odds FC (2003) Synergy, antagonism and what the chequerboard puts between them. J Antimicrob Chemother 52: 1 .

32. Pillai SK, Moellering RC Jr, Eliopoulos GM (2005) Antimicrobial combinations. Antibiotics in laboratory medicine (5th edn) Lippincott Williams and Wilkins, Philadelphia.

33. White RL, Burgess DS, Manduru M, Bosso JA (1996) Comparison of three different in vitro methods of detecting synergy: time-kill, checkerboard, and E test. Antimicrob Agents Chemother 40: 1914-1918.

34. Sopirala MM, Mangino JE, Gebreyes WA, Biller B, Bannerman T, et al. (2010) Synergy testing by etest, microdilution checkerboard, and time-kill methods for pan-drug-resistant Acinetobacter baumannii. Antimicrob Agents Chemother 54: 4678-4683.

35. Jarlier V, Nicolas MH, Fournier G, Philippon A (1988) Extended broadspectrum beta-lactamases conferring transferable resistance to newer beta-lactam agents in Enterobacteriaceae: hospital prevalence and susceptibility patterns. Rev Infect Dis 10: 867-878.

36. Leclercq R (2002) Mechanisms of resistance to macrolides and lincosamides: nature of the resistance elements and their clinical implications. Clin Infect Dis 34: 482-492.

37. Leclercq R, Courvalin P (1991) Intrinsic and unusual resistance to macrolide, lincosamide and streptogramin antibiotics in bacteria. Antimicrob Agents Chemother 35: 1273-1276.

38. Yilmaz G, Aydin K, Iskender S, Caylan R, Koksal I (2007) Detection and prevalence of inducible clindamycin resistance in Staphylococci. J Med Microbiol 56: 342-345.

39. Dunning T (2006) Caring for the wounded healer-nurturing the self. J Bodywork Movement Therapies 10: 251-260.

40. Mabrouk MI (2012) Synergistic and antibacterial activity of six medicinal plants used in folklore medicine in egypt against E. coli O157: H7. J Appl Sci Res 8: 1321-1327.

41. Shealy CN (1998) The Illustrated Encyclopedia of Healing Remedies, Element Books, Rockport, Mass, USA.

42. Rapper S, Kamatou G, Viljoen A, van Vuuren S (2013) The In Vitro Antimicrobial activity of Lavandula angustifolia essential oil in combination with other aroma-therapeutic oils. Evid Based Complement Alternat Med 2013: 852049.

43. Houghton P (2009) Synergy and polyvalence: paradigms to explain the activity of herbal products (6th edn.) Evaluation of Herbal Medicinal Products: Perspectives on quality, safety and efficacy. Pharmaceutical Press.

44. Stahl-Biskup E, Sáez F (2002) Thyme: The genus Thymus. Taylor and Francis.

45. Iten F, Saller R, Abel G, Reichling J (2009) Additive antimicrobial effects of the active components of the essential oil of Thymus vulgarischemotype carvacrol. Planta Med 75: 1231-1236.

46. Levic J, Cabarkapa I, Todorovic G, Pavkov S, Sredanovic S, et al. (2011) In vitro antibacterial activity of essential oils from plant family Lamiaceae. Roman Biotechnol Lett 16: 6034-6041.

47. Tohidpour A, Sattari M, Omidbaigi R, Yadegar A, Nazemi J (2010) Antibacterial effect of essential oils from two medicinal plants against 
Methicillin-resistant Staphylococcus aureus (MRSA). Phytomedicine 17 $142-145$.

48. Kon, K, Rai M (2012) Antibacterial activity of Thymus vulgaris essential oil alone and in combination with other essential oils. Bioscience 4: 2087-3956.

49. Ultee A, Benni MHJ, Moezelaar R (2002) The phenolic hydroxyl group of carvacrol is essential for action against the foodborne pathogen Bacillus cereus. Appl Environ Microbiol 68: 1561-1568.

50. García-García R, López-Malo A, Palou E (2011) Bactericidal action of binary and ternary mixtures of carvacrol, thymol, and eugenol against Listeria innocua. J Food Sci 76: M95-M100.

51. Ross ZM, O' Gara EA, Hill DJ, Sleightolme HV, Maslin IJ (2001) Antimicrobial properties Antimicrobial properties of garlic oil against human enteric bacteria: Evaluation of methodologies and comparisons with garlic oil, sulfides and garlic powder. Appl Environ Microbiol 67: 475-480.

52. Eja ME, Arikpo GE, Enyi-Idoh KH, Ikpeme EM (2011) An evaluation of the antimicrobial synergy of Garlic (Allium sativum) and Utazi (Gongronema latifolium) on Escherichia coli and Staphylococcus aureus. Malaysian J Microbiol 7: 49-53.

53. Ali H, Dixit S (2012) In vitro antimicrobial activity of flavanoids of Ocimum sanctum with synergistic effect of their combined form. Asian Pac J Trop Disease 2: S396-S398.

54. Braquet P (1988) The ginkgolides from chinese pharmacopeia to a new class of pharmacological agents: The antagonists of platelet activating factor (2nd edn) In Ginkgolides-Chemistry, Biology, Pharmacology and Chemical Perspectives, Science.

55. Yang L, Wang CZ, Ye JZ, Li HT (2011) Hepatoprotective effects of polyprenols from $\mathrm{GBL}$ on $\mathrm{CCl}_{4}$-induced hepatotoxicity in rats. Fitoterapia 82: 834-840.

56. Tao R, Wang CZ, Kong ZW (2013) Antibacterial/antifungal activity and synergistic interactions between polyprenols and other lipids isolated from Ginkgo Biloba L. leaves. Molecules18: 2166-2182.

57. Ahmed M, Djebli N, Aissat S, Zerrouki K, Bourabeh A (2013) In vitro synergistic antibacterial activity of natural honey combined with curcuma starch and their correlation with diastase number, flavonoid and polyphenol content. J Plant Pathol Microb 4: 152.

58. Heep M, Rieger U, Beck D, Lehn N (2000) Mutations in the beginning of the rpoB gene can induce resistance to rifamycins in both Helicobacter pylori and Mycobacterium tuberculosis. Antimicrob Agents Chemother 44: 1075-1077.

59. Wright GD (2005) Bacterial resistance to antibiotics: enzymatic degradation and modification. Adv Drug Deliv 57: 1451-1470.

60. Nikaido H, Vaara M (1985) Molecular basis of bacterial outer membrane permeability. Microbiol 49: 1-32.

61. Renau TE, Leger R, Flamme EM, Sangalang J, She MW, et al. (1999) Inhibitors of efflux pumps in Pseudomonas aeruginosa potentiate the activity of fluoroquinolone antibacterial leuofloxacin. J Med Chem 42: 4928-4931.

62. Hemaiswarya S, Kruthiventib AK, Doble M (2008) Synergism between natural products and antibiotics against Infectious diseases. Phytomedicine 15: 639-652.

63. Lorenzi V, Muselli A, Bernardini AF, Berti L, Pages JM, et al. (2009) Geraniol restores antibiotic activities against multidrug-resistant isolates from gram-negative species. Antimicrob Agents Chemother 53: 2209-2211.

64. Bedi MS, Verma V, Chhibber S (2009) Amoxicillin and specific bacteriophage can be used together for eradication of biofilm of Klebsiella pneumoniae B5055. World J Microbiol Biotech 25: 1145-1151.

65. Birla SS, Tiwari VV, Gade AK, Ingle AP, Yadav AP, et al. (2009) Fabrication of silver nanoparticles by Phoma glomerata and its combined effect against Escherichia coli, Pseudomonas aeruginosa and Staphylococcus aureus. Lett Appl Microbiol 48: 173-179.
66. Brackman G, Cos P, Maes L, Nelis HJ, Coenye T (2011) Quorum sensing inhibitors increase the susceptibility of bacterial biofilms to antibiotics in vitro and in vivo. Antimicrob Agents Chemother 55: 2655-2661.

67. Lehtinen J, Lilius EM (2007) Promethazine renders Escherichia coli susceptible to penicillin G: real-time measurement of bacterial susceptibility by fluoro-luminometry. Int J Antimicrob Agents 30: 44-51.

68. Ettayebi K, Yamani JE, Rossi-Hassani B (2000) Synergistic effect of nisin and thymol on antimicrobial activities in Listeria monocytogenes and Bacillus subtilis. FEMS Microbiol Lett 183: 191-195.

69. Tiwari RP, Bharti SK, Kaur HD, Dikshit RP, Hoondal GS (2005) Synergistic antimicrobial activity of tea \& antibiotics. Indian J Med Res 122: $80-84$.

70. Garo E, Eldridge GR, Goering MG, DeLancey Pulcini E, Hamilton MA, et al. (2007) Asiaticacid and corosolic acid enhance the susceptibility of Pseudomonas aeruginosa biofilms to tobramycin. Antimicrob Agents Chemother 51:1813-1817.

71. Horiuchi K, Shiota S, Kuroda T, Hatano T, Yoshida T, et al. (2007) Potentiation of antimicrobial activity of aminoglycosidesby carnosol from Salvia officinalis. Biol Pharm 30: 287-290.

72. Lim YH, Kim IH, Seo JJ (2007) In vitro activity of kaempferol isolated from Impatiens balsamina alone and in combination with erythromycin and clindamycin against Propionibacterium acnes. J Microbiol 45: $473-477$

73. Chusri S, Villanueva I, Voravuthikunchai SP, Davies J (2009) Enhancing antibiotic activity: a strategy to control Acineto bacter infections. J Antimicrob Chemother 64: 1203-1211.

74. Lima CF, Andrade PB, Seabra RM, Ferreira FM, Pereira WC (2005) The drinking of a Salvia officinalis infusion improves liver antioxidant status in mice and rats. J Ethnopharmacology 97: 383-389.

75. Stanojevic D, Comic L, Stefanovic O, Solujic SS (2010) In vitro synergistic antibacterial activity of Salvia officinalis $L$ and some preservatives. Arch Biol Sci 62: 175-183.

76. Ge F, Zeng F, Liu S, Guo N, Ye H, et al. (2010) In vitro synergistic interactions of oleanolic acid in combination with isoniazid, rifampicin or ethambutanol against Mycobacterium tuberculosis. J Med Microbiol 59: 567-572.

77. Shaaban HA, Ahmed MBM, Sideek LEE, Amer MM (2013) Study on the antimicrobial activity and Synergistic/antagonistic effect of interactions between antibiotics and some spice essential oils against pathogenic and food-spoiler microorganisms. J App Sci Res 9: 5076-5085.

78. Facundo VA, Silveira ASP, Morais SM (2005) Constituents of Piper alatabaccum Trel \& Yuncker (Piperaceae). Biochem Systemat Ecol 33: 753-756

79. Puhl MCMN, Cortez DAG, Ueda NT, Nakamura CV, Filho BPD (2011) Antimicrobial Activity of Piper gaudichaudianum Kuntze and its Synergism with Different Antibiotics. Molecules 16: 9925-9938.

80. Stefanovio OD, Stanojevic DD, Omio LR (2012) Synergistic antibacterial activity of Salvia officinalis and Cichorium intybus extracts and antibiotics. Acta Pol Pharm Drug Res 69: 457-463.

81. Betts JW, Murphy C, Kelly SM, Haswell SJ (2012) Synergistic antibacterial effects of the aflavin in combination with ampicillin against hospital isolates of Stenotrophomonas maltophilia. J Microbiol Biotech Food Sci 2: 1068-1078.

82. Wolska K, Grzes K, Kurek A (2012) Synergy between novel antimicrobials and conventional antibiotics or bacteriocins. Polish J Microbio 161: 95-104.

83. Mahboubi M (2013) Iranian medicinal plants as antimicrobial agents. J Microbiol Biotech Food Sci 2: 2388-2405.

84. Thakur P, Chawla R, Chakotiya AS, Tanwar A, Goel R, et al. (2015) Camellia sinensis ameliorates the efficacy oflast line antibiotics against carbapenem resistant Escherichia coli. Phytother Res 30: 314-322.

85. Randhawa GK, Kullar JS, Rajkumar (2011) Bioenhancers from mother nature and their applicability in modern medicine. Int J App Basic Med Res 1: 5-11. 
86. Ejim L, Farha MA, Falconer SB, Wildenhain J, Coombes BK, et al. (2011) Combinations of antibiotics and nonantibiotic drugs enhance antimicrobial efficacy. Nat Chem Biol 7: 348-350.

87. Elumalai S, Kesavan R, Ramganesh S, Murugasen R (2011) Isolation, purification and identification of the antidiabetic components from Cinnamomum zeylanicum and Cinnamomum cassia bark oil extracts. Curr Bot 2: 12-17.

88. Singh G, Mayura S, De Lampasona MP, Catalan CAN (2007) A comparison of chemical, antioxidant and antimicrobial studies of cinnamon leaf and bark volatile oils, oleoresins and their constituents. Food Chem Toxicol 45: 1650-1661.

89. Friedman M, Henika PR, Mandrell RE (2002) Bactericidal activities of plant essential oils and some of their isolated constituents against Campylobacter jejuni, Escherichia coli, Listeria monocytogenes and Salmonella enterica. J Food Protec 65: 1545-1560.

90. Faix S, Faixova Z, Placha I, Koppel J (1995) Effect of Cinnamomum zeylanicum essential oil on antioxidative status in broiler chickens. Thai Herbal Pharmacopoeia I Prachachon Co Ltd., p: 38.

91. Tyagi AK, Malik A (2010) Liquid and vapour phase antifungal activities of selected essential oils against Candida albicans: microscopic observations and chemical characterization of Cymbopogon citratus. BMC Complement Altern Med 10: 65.

92. Schmidt E, Jirovetz L, Buchbauer G, Eller GA, Stoilova I, et al. (2008) Composition and Antioxidant Activities of the Essential Oil of Cinnamon (Cinnamomum zeylanicum Blume) Leaves from Sri Lanka. Jeobp 9: 170-182.

93. Javaprakash GK, Rao LJ, Sakariah KK (2002) Chemical composition of volatile oil from Cinnamomum zeylanicum buds. Z Naturforsch 57: 990.

94. Monzote L, García M, Montalvo AM, Scull R, Miranda M, et al. (2007) In vitro activity of an essential oil against Leishmania donovani. Phytother Res 21: 1055-1058.

95. Jenner PM, Hagan EC, Taylor JM, Cook EL, Fitzhugh OG (1964) Food flavourings and compounds of related structure. Food Chem Toxicol 2: 327-343.

96. Aggarwal KK, Ahmed A, Santha TRK, Jain N, Gupta SK, et al. (2000) Antibacterial activity spectra of Pelargonium graveolens $L$. and cymbopogon winterrianus Jowitt oil constituents and acyl derivatives. J Med Aroma Plant Sci 22: 544-548.

97. Wendakoon CN, Morihiko S (1995) Inhibition of amino acid decarboxylase activity of Enterobacter aerogenes by active components in spices. J Food Prot 58: 280-283.

98. Suresh P, Ingle VK, Vijayalakshima V (1992) Antibacterial activity of eugenol in comparison with other antibiotics. J Food Sci Technol 29: 254-256.

99. Feron VJ, Til HP, DeVrijer F, Woutersen RA, Cassee FR, et al. (1991) Aldehydes: occurrence, carcinogenic potential, mechanism of action and risk assessment. Mutat Res 259: 363-385.

100. Kwon JA, Yu CB, Park HD (2003) Bacteriocidal effects and inhibition of cell separation of cinnamic aldehyde on Bacillus cereus. Lett Appl Microbiol 37: 61-65.

101. Hemaiswarya S, Soudaminikkutty R, Narasumani ML, Doble M (2011) Phenylpropanoids inhibit protofilament formation of Escherichia coli cell division protein. Ftsz J Med Microbiol 60: 1317-1325.

102. Helander IM, Alakomi HL, Latva KK, Mattila ST, Pol I, et al. (1998) Characterization of the action of selected essential oil components on Gram-negative bacteria. J Agricul Food Chem 6: 3590-3595.

103. Ali SM, Khan AA, Ahmed I, Musaddiq M, Ahmed KS, et al. (2005) Antimicrobial activities of eugenol and cinnamaldehyde against the human gastric pathogen Helicobacter pylori. Ann Clin Microbiol Antimicrob 4: pp20.

104. Yossa N, Patel J, Macarisin D, Millner P, Murphy C, et al. (2012) Antibacterial activity of cinnamaldehyde and sporan against Escherichia coli O157:H7 and Salmonella. J Food Proc Pres 1: 1.

105. Hoque MD, Inatsu ML, Juneja V, Kawamoto S (2007) Antimicrobial activity of clove and cinnamon extracts against food borne pathogens and spoilage bacteria and inactivation of Listeria monocytogenes in ground chicken meat with their essential oils. J Food Sci Tech 72: 9-21.

106. Babu AJ, Sundari AR, Indumathi J, Surjan RVN, Sravanthi M (2011) Study on the Antimicrobial activity and Minimum Inhibitory Concentration of Essential Oils of Spices. Vet World 4: 311-316.

107. Yap PSX, Lim SHE, Hu CP, Yiap BC (2013) Combination of essential oils and antibiotics reduce antibiotic resistance in plasmid-conferred multidrug resistant bacteria. Phytomedicine 20: 710-713.

108. Goni P, Lopez P, Sanchez C, Gomez LR, Becerril R, et al. (2009) Antimicrobial activity in the vapour phase of a combination of cinnamon and clove essential oils. Food Chem 116: 982-989.

109. Zeid AAA, Shalaby MA, Aziz MIMA (2010) Control of some multiresistant bacteria infecting upper respiratory system using certain essential oils and plant extracts. Proceeding of fifth scientific environmental conference. Zagazig Uni, pp: 87-105.

110. Nostro A, Marino A, Blanco AR, Cellini L, Di Giulio M, et al. (2009) In vitro activity of carvacrol against staphylococcal preformed biofilm by liquid and vapour contact. J Med Microbiol 158: 791-797.

111. Nabavi SM, Marchese A, Izadi M, Curti V, Daglia M, et al. (2015) Plants belonging to the genus Thymus as antibacterial agents: From farm to pharmacy. Food Chem 173: 339-347.

112. Figiel A, Antoni S, Antonio GO, Barrachina C, Angel A (2010) Composition of oregano essential oil (Origanum vulgare) as affected by drying method. J Food Eng 98: 240-247.

113. Poulose AJ, Croteau R (1978) Biosynthesis of aromatic monoterpenes: conversion of gterpinene to $\mathrm{p}$-cymene and thymol in Thymus vulgaris $\mathrm{L}$. Arch Biochem Biophys 187: 307-314.

114. Veldhuizen EJ, Tjeerdsma V, Bokhoven JL, Zweijtzer C, Burt SA, et al. (2006) Structural requirements for the antimicrobial activity of carvacrol. J Agri Food Chem 54: 1874-1879.

115. Robledo S, Osorio E, Munoz D, Jaramillo LM, Resterepo A, et al. (2005) in vitro and in vivo cytotoxicities and antilashmanial activities of thymol and hemisynthetic derivatives. Antimicrob Agents Chemother 49: 1652-1655.

116. Fenaroli $G$ (1995) Fenaroli's handbook of flavor ingredients.

117. Ultee A, Kets EPW, Smid EJ (1999) Mechanisms of action of carvacrol on the food-borne pathogen Bacillus cereus. Appl Environ Microbiol 65: 4606-4610.

118. Suntres ZE, Coccimiglio J, Alipour M (2015) The bioactivity and toxicological actions of carvacrol. Criti Rev Food Sci Nutr 55: 304-318.

119. Botelho MA, Nogueira NAP, Bastos GM, Fonseca SGC, Lemos TLG, et al. (2007) Antimicrobial activity of the essential oil from Lippiasidoides, carvacrol and thymol against oral pathogens. Braz J Med Bio 40: 349-356.

120. Perez CD, Cao J, Chen L, McLandsboroug L, Weiss J (2011) Inactivation of Listeria monocytogenes and Escherichia coli O157:H7 biofilms by micelle-encapsulated eugenol and carvacrol. J Food Prot 74: 55-62.

121. Di Pasqua R, Betts G, Hoskins N, Edwards M, Ercolini D, et al. (2007) Membrane toxicity of antimicrobial compounds from essential oils. J Agric Food Chem 55: 4863-4870.

122. Friedman M, Henika PR, Levin CE, Mandrell RE (2004) Bacterial activities of plant essential oils and their components against Escherichia coli O157:H7 and Salmonella enterica in apple juice. J Agricul Food Chem 52: 6042-6048.

123. Kisko G, Roller S (2005) Carvacrol and p-cymene inactivate Escherichia coli O157:H7 in apple juice. BMC Microbiol 5: 36.

124. Solomakos N, Govaris A, Koidis P, Botsoglou N (2008) The antimicrobial effect of thyme essential oil, nisin, and their combination against Listeria monocytogenes in minced beef during refrigerated storage. Food Microbiol 25: 120-127.

125. Nazer AI, Kobilinsky A, Tholozan JL, Dubois BF (2005) Combinations of food antimicrobials at low levels to inhibit the growth of Salmonella typhimurium: a synergistic effect. Food Microbiol 22: 391-398.

126. Zhou F, Ji B, Zhang H, Jiang H, Yang Z, et al. (2007) The antibacterial effect of cinnaldehyde, thymol, carvacrol and their combinations against 
Citation: Bhardwaj M, Singh BR, Sinha DK, Kumar V, Prasanna Vadhana OR, et al. (2016) Potential of Herbal Drug and Antibiotic Combination Therapy: A New Approach to Treat Multidrug Resistant Bacteria. Pharm Anal Acta 7: 523. doi:10.4172/2153-2435.1000523

Page 14 of 14

the foodborne pathogen Salmonella typhimurium. J Food Safety 27 124-133.

127. Zhou F, Ji B, Zhang H, Jiang H, Yang Z, et al. (2007) Synergistic effect of thymol and carvacrol combined with chelators and organic acids against Salmonella typhimurium. J Food Prot 70: 1704-1709.

128. Karatzas AK, Kets EPW, Smid EJ, Bennik MHJ (2001) The combined action of carvacrol and high hydrostatic pressure on Listeria monocytogenes. Scott A J Appl Microbiol 90: 463-469.

129. Si H, Hu J, Liu Z, Zeng ZL (2008) Antibacterial effect of oregano essential oil alone and in combination with antibiotics against extended-spectrum $\beta$-lactamase producing Escherichia coli. FEMS Immunol Med Microbiol 53: 190-194.

130. Gallucci N, Casero C, Oliva M, Zygadlo J, Demo M (2006) Interaction between terpenes and penicillin on bacterial strains resistant to betalactam antibiotics. Mol Med Chem 10: 30-32.

131. Palaniappan K, Holley RA (2010) Use of natural antimicrobials to increase antibiotic susceptibility of drug resistant bacteria. Int J Food Microbiol 140: 164-168.
132. Yue GF, Wei J, Qian XP, Yu LX, Zou ZY, et al. (2013) Synergistic anticancer effects of polyphyllin I and evodiamine on freshly-removed human gastric tumors. PLoS ONE 8: e65164.

133. Li XX, Xu X, Wang JN, Yu H, Wang X, et al (2012) A system- level investigation into the mechanisms of Chinese Traditional Medicine: compound Danshen Formula for cardiovascular disease treatment. PLoS ONE 7: e43918.

134. Wang XJ, Zhang AH, Wang P, Sun H, Wu GL, et al. (2013) Metabolomics coupled with proteomics advancing drug discovery toward more agile development of targeted combination therapies. Mol Cell Proteom 12: 1226-1238.

135. Gupta VK (2013) Project on Development of alternative therapy for calf diarrhea. IVRI, Izatnagar, Uttar Pradesh, India. 